Research Article

\title{
New Cost-effective RP-HPLC Method Development and Validation for Quantitative Estimation of Ivacaftor in Pharmaceutical Formulation
}

\author{
Roshani Singh*, L K Omray, Pushpendra Soni \\ Radharaman Institute of Pharmaceutical Sciences, Bhopal, Madhya Pradesh, India \\ *Corresponding author's E-mail: sroshani74@gmail.com
}

Received: 03-08-2021; Revised: 16-10-2021; Accepted: 28-10-2021; Published on: 15-11-2021.

\begin{abstract}
In this article "new cost-effective RP-HPLC method development and validation for quantitative estimation of ivacaftor in the pharmaceutical formulation" developed. This study includes RP-HPLC Spectrophotometric method development, such as economical and simple HPLC method was optimized during development and validated accordingly in tablets of ivacaftor. The developed method may utilize for the analysis of ivacaftor at the laboratory level. The result shows that developed methods are cost-effective, rapid (Short retention time), simple, accurate (the value and \%RSD between 2-5), precise, and can be used for the intended purpose on the tablet dosage form. The present proposed method is capable of better separation of analyte and qualifies on the point of analytical validation such as linearity, specificity, accuracy, precision, robustness, LOD, and LOQ on a marketed formulation. The simplicity, rapidity, and reproducibility of the developed method qualify the objective of the research. Results of analysis of the ivacaftor tablet formulations are arranged in the experimental, result, and discussion section. The portion of ivacaftor found in terms of quantity was between $98-102 \%$ and also within USP 29 chapter (541) acceptance criteria.
\end{abstract}

Keywords: Cystic fibrosis, validation, adsorption chromatography, ich guidelines, spectroscopic system.

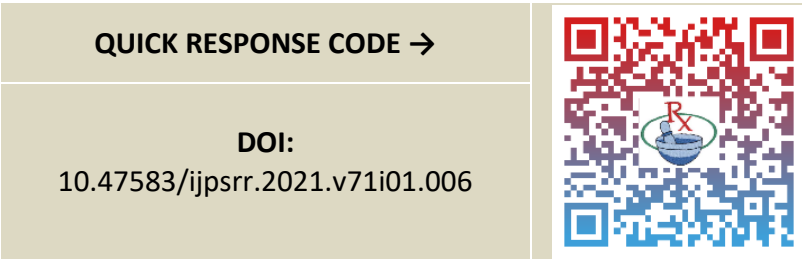

DOI link: http://dx.doi.org/10.47583/ijpsrr.2021.v71i01.006

\section{INTRODUCTION}

V alidation of method is the process that is used to guarantee that the strategy of analytical parameters applied for a specific test is appropriate for its quality intended purpose. Summary of experimental results from method validation used to confirm the reliability, quality, reproducibility of analytical aspects. ${ }^{1-3}$

These are the parameters valid for developing new methods of analysis:

This method may not be suitable for certain analysis analyzes for a special sample pool. When any existing method too expensive, time-consuming, or energyconsuming or May not easily adaptable during automation ${ }^{4-5}$ The current intended method may not be adequate for selectivity and sensitivity to provide acceptable parameters in all conditions. Current methods may compose a lot of errors, non-artifact, and/or adulterated methods, or they may be irreproducible (serve poor accuracy or precision). ${ }^{6-7}$ Latest techniques with new instrumentation may provide an opportunity to improve the existing method as a new one. May improve analyte identification or detection capacity, perfect accuracy or precision or better output on investment. ${ }^{8-11}$
The solute present in the mobile phase passes through the column or plate in the chromatography technique. The passage of solute or test sample is called chromatographic development. ${ }^{12}$ Chromatographic development is mainly tree types

1. Elution development

2. Displacement development

3. Frontal analysis

Elution development is mainly used in gas chromatography and liquid chromatography but sometimes displacement technique is used in preparative liquid chromatography. In thin-layer chromatography, multi-sample solvent development is based on the frontal analysis but it is sometimes confused that's based on the mobile phase passage. ${ }^{13-14}$

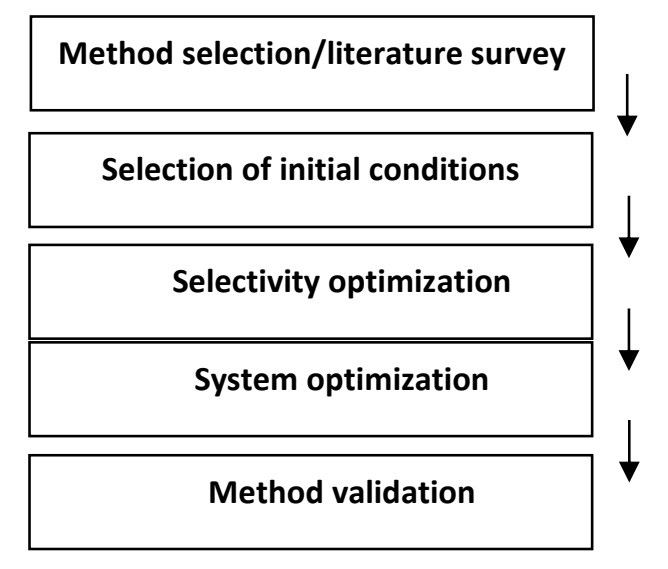

Figure 1: The development process in chromatography 
The quantitative estimation of the active constituents is an integral part of the developing and manufacturing process of pharmaceutical dosage forms. Slight changes in the composition or in the purity of the drug itself can affect the therapeutic value. ${ }^{15-16}$ Therefore, there is a need for the development of better and reliable methods for the estimation of the pharmaceutical dosage form. New methods however have to be devised and developed for the estimation of the drugs. ${ }^{17-18}$

The official methods for the analysis of active ingredients of formulations are few and most of the methods available for the analysis of active ingredients are applicable only after prior separation that involves tedious and timeconsuming procedures. ${ }^{19-20}$

Therefore, in the present study, an attempt is made to develop the RP-HPLC method for the analysis and method development of the drug in pure and pharmaceutical formulations. ${ }^{(21)}$ This research study aims to develop and validate simple, accurate, precise, sensitive, and costeffective RP-HPLC method for quantitative evaluation of Ivacaftor in pharmaceutical formulations,

Which is critical for the quality control laboratories?

Ivacaftor synthetic is a quinoline and used to treat cystic fibrosis, it was approved by the Food and Drug Administration on January 31, 2012. Each tablet/ granule of Ivacaftor contains the commonly prescribed daily doses of $150 \mathrm{mg} .{ }^{23-23}$

\section{MATERIALS AND METHODS}

The present work has been done on Agilent HPLC. It has 6029 series pumps, an auto sampler with a 100-microlitre loop, U.V. Vis. Detector, Inertsil ODS 3V-C18 column (4.6 x $250 \mathrm{~mm}, 5 \mu$ particle size) with Chromalion 6.8 version software. Chemicals/Reagents used are Acetonitrile, Methanol, Ortho-phosphoric acid Water. ${ }^{24}$

\section{Diluent}

Prepared a mixture of acetonitrile and methanol in the ratio of $(60: 40 \mathrm{v} / \mathrm{v})$ sonicated for 10 minutes.

\section{Mobile Phase}

Prepared a mixture of acetonitrile and methanol in the ratio of $(60: 40 \mathrm{ml} \mathrm{v/v})$ sonicated for 10 minutes, allowed to attain room temperature. ${ }^{25}$

\section{Preparation of standard stock solution}

Transfer an accurately weighed $25 \mathrm{mg}$ of Ivacaftor standard into a $50 \mathrm{ml}$ volumetric flask, added $30 \mathrm{ml}$ of diluent, and sonicated to dissolve. Make volume up to the mark with diluent and mixed well. Diluted $5 \mathrm{ml}$ of above standard stock to $50 \mathrm{ml}$ with diluent and mixed well. ${ }^{26-27}$

\section{Preparation of sample Stock Solution:}

Marketed formulation 20 tablets of Ivacaftor were taken and calculate average weight than made a fine powder with the help of mortar pestle. ${ }^{(28)}$ The powder equivalent to $100 \mathrm{mg} \approx$ of Ivacaftor was taken and into $100 \mathrm{ml}$ volumetric flask added $65 \mathrm{ml}$ of acetonitrile sonicated for 30 minutes with intermittent shaking, allowed to attain room temperature make volume up to the mark with methanol and mixed. Centrifuge solution at $3500 \mathrm{rpm}$ for 10 minutes. The resulting concentration of test sample $1 \mathrm{mg} / \mathrm{ml}$ (1000 PPM) of Ivacaftor was used in further study and validation. ${ }^{29-30}$

\section{RESULT AND DISCUSSION}

\section{Physical Characterization}

In this study physical properties on the observation basis were recorded by spreading Ivacaftor powder in Petri plate.

\section{Physical Nature - Crystalline powder}

2. Colour - off white

3. Odour - Odourless

4. Taste - Pungent

\section{Solubility Study}

Weighed accurately 1 gram of Ivacaftor powder 6 times and transferred in Six different $100 \mathrm{ml}$ volumetric flasks, then add solvent in required quantity respectively. Sonicated and observed solubility and precipitation within the account on mind clearness of solvent system with Ivacaftor powder. See below for solubility behavior.

Table 1: Solubility behavior of ivacaftor

\begin{tabular}{|c|c|c|}
\hline S.no. & Solvent & Physical Behavior \\
\hline 1 & Dimethyl sulfoxide & Soluble \\
\hline 2 & Methanol & Freely Soluble \\
\hline 3 & Water & Sparingly Soluble \\
\hline 4 & Ethanol & Soluble \\
\hline 5 & pH 6.8 Phosphate Buffer & Soluble \\
\hline 6 & Acetonitrile & Freely Soluble \\
\hline
\end{tabular}

\section{Melting Point}

Taken capillary and filled with Ivacaftor capillary with thermometer then dip it into the tube which previously contains liquid paraffin, heat gently with burner and record the degree of melting of Ivacaftor. The melting point of the Ivacaftor record from $291^{\circ} \mathrm{C}$ to $295^{\circ} \mathrm{C}$ and the final melting point of the Ivacaftor is $293^{\circ} \mathrm{C}$.

\section{Infrared Spectral Analysis}

Taken $2 \mathrm{mg}$ of Ivacaftor with $400 \mathrm{mg}$ of potassium bromide in mortar pestle then mixed well and made a uniform fine mixture.

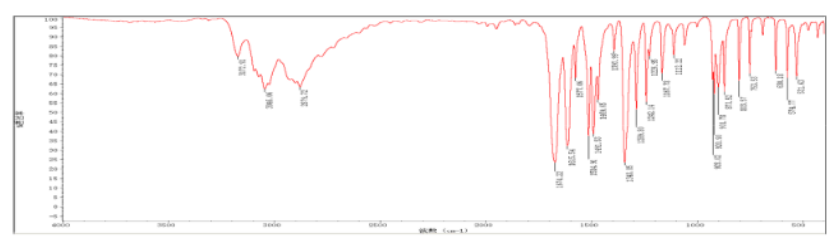

Figure 2: IR Spectra of Ivacaftor 
The Ivacaftor solution was scanned on a UV spectrophotometer at $200-400 \mathrm{~nm}$ to determine $\lambda_{\max }$. Maximum absorbance showed on $\mathbf{2 2 5} \mathbf{~} \mathbf{~ m}$.

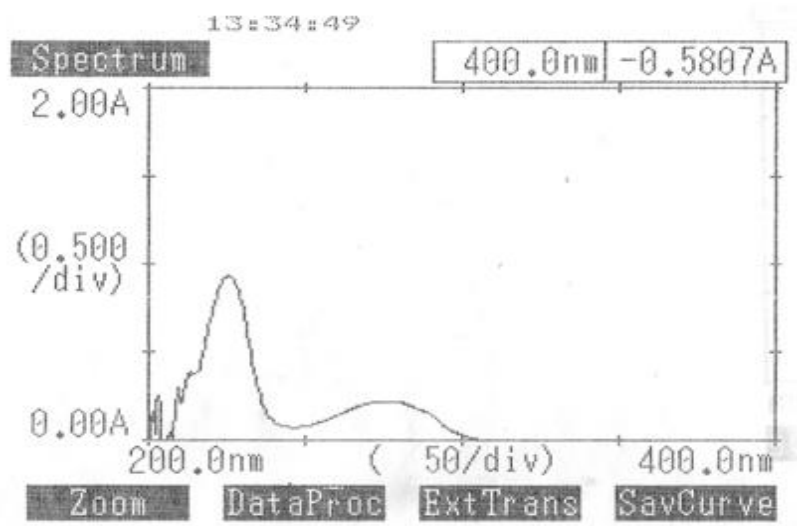

Figure 3: Determination of $\lambda$ max of Ivacaftor

An analytical method, a series of dilutions ranging from 5$25 \mu \mathrm{g} / \mathrm{ml}$ was prepared in the diluent. Absorbance was recorded at $225 \mathrm{~nm}$. A calibration graph was plotted

Between absorbance and respective concentration and the regression equation was derived.

Table 2: Linearity of ivacaftor

\begin{tabular}{|c|c|c|}
\hline $\begin{array}{c}\text { Concentration } \\
(\mu \mathrm{g} / \mathrm{ml})\end{array}$ & Absorbance & Statistical Analysis \\
\hline 5 & 0.1547 & Slope $=0.0337$ \\
\hline 10 & 0.3192 & \\
\hline 15 & 0.4803 & Intercept $=0.0188$ \\
\hline 20 & 0.6454 & \\
\hline 25 & 0.8341 & $\begin{array}{c}\text { Correlation coefficient } \\
=0.999\end{array}$ \\
\hline
\end{tabular}

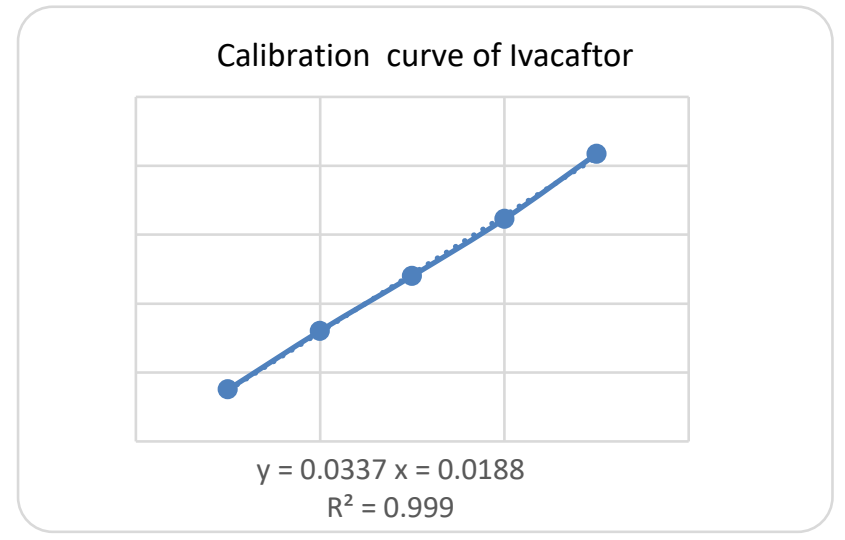

Figure 4: Calibration curve of ivacaftor using UV spectrophotometer

\section{Validation of Developed Method \\ Linearity}

After analysis of five different (from 5 to $25 \mu \mathrm{g} / \mathrm{ml}$ ) concentrations and areas for each concentration were recorded.
Table 3: Response ratio data for linearity of ivacaftor

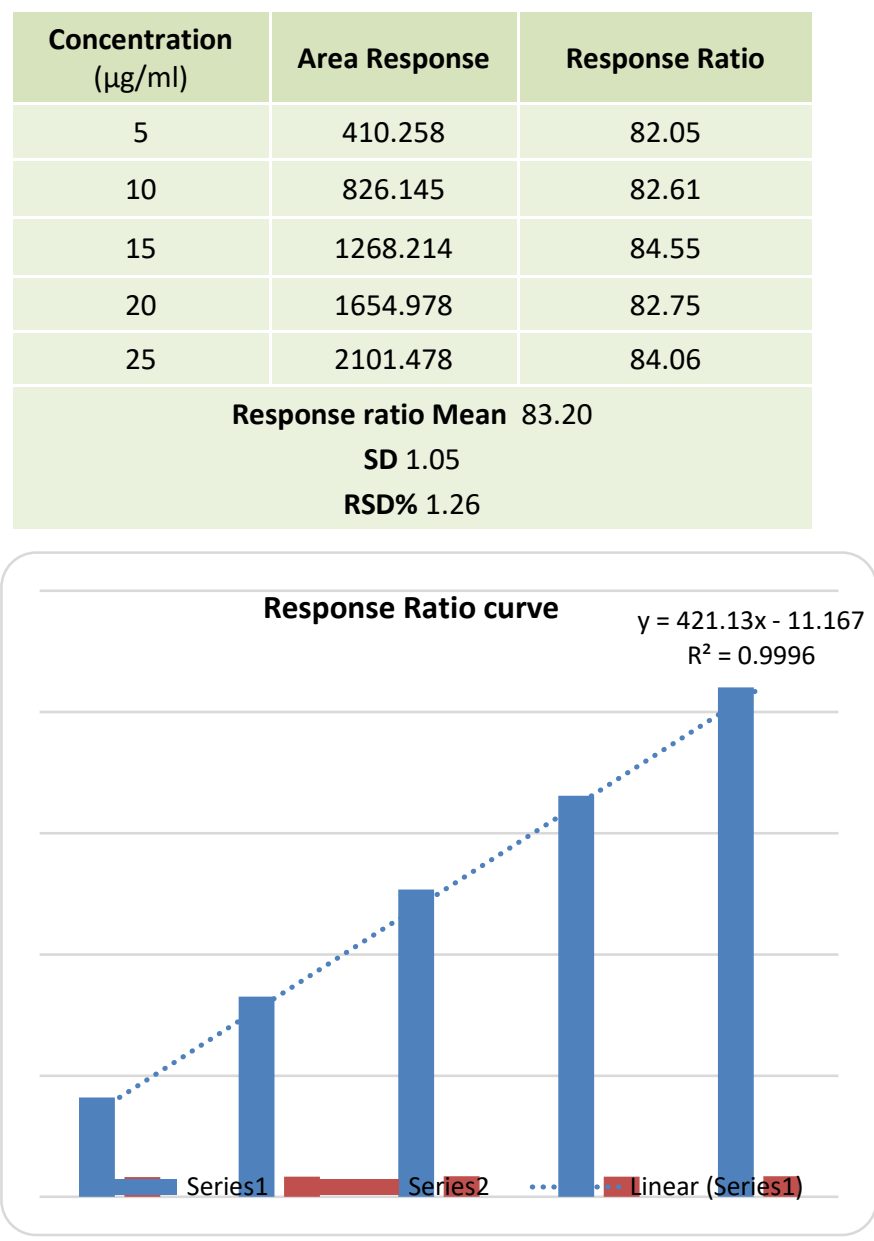

Figure 5: Response ratio curve of ivacaftor

\section{Specificity}

Chromatogram of Ivacaftor at 5.81 Minutes retention time

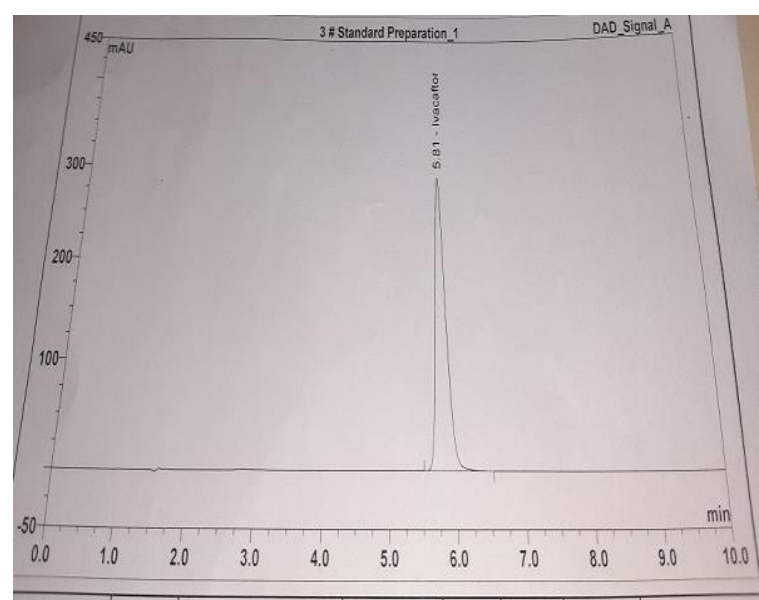

Figure 6: Chromatogram of ivacaftor

\section{Accuracy\& Recovery}

Applying the analytical procedure of the standard sample from the range of $80 \%, 100 \%$, and $120 \%$ level of the test concentration. 


\section{Recovery is calculated as}

Area of test $\times$ dilution of std. $\times$ potency

Conc. obtained $=$

Area of std. $x$ dilution of test

Table 4: Recovery studies of ivacaftor formulation

\begin{tabular}{|c|c|c|c|c|}
\hline $\begin{array}{c}\text { Initial } \\
\text { Amount of stock }(\mathrm{mg})[\mathrm{A}]\end{array}$ & $\begin{array}{l}\text { Addition of known } \\
\text { quantity }(\mathrm{ml})[\mathrm{B}]\end{array}$ & $\begin{array}{l}\text { Final Conc. } \\
\qquad(\mu \mathrm{g} / \mathrm{ml})\end{array}$ & \% Recovery & $\begin{array}{c}\text { Average } \\
\text { Recovery } n=3\end{array}$ \\
\hline \multirow{3}{*}{100} & \multirow{3}{*}{2} & \multirow{3}{*}{80} & 98.82 & \multirow{3}{*}{99.5} \\
\hline & & & 97.97 & \\
\hline & & & 101.85 & \\
\hline \multirow{3}{*}{100} & \multirow{3}{*}{2.5} & \multirow{3}{*}{100} & 99.54 & \multirow{3}{*}{99.9} \\
\hline & & & 101.97 & \\
\hline & & & 98.07 & \\
\hline \multirow{3}{*}{100} & \multirow{3}{*}{3.0} & \multirow{3}{*}{120} & 101.17 & \multirow{3}{*}{99.7} \\
\hline & & & 98.71 & \\
\hline & & & 99.22 & \\
\hline
\end{tabular}

\section{Precision}

The precision is established in three differences:

1. Repeatability

2. Intermediate precision

a) Day to day b) Analyst to analyst

\section{Repeatability}

Ivacaftor sample which is prepared for accuracy as 100

$\mu \mathrm{g} / \mathrm{ml}$ here utilized for repeatability study.

Table 5: Repeatability of Ivacaftor

\begin{tabular}{|c|c|c|c|c|}
\hline Injection No. & Concentration & Area Response & Tailing Factor & Theoretical Plate \\
\hline 1 & $100 \mu \mathrm{g} / \mathrm{ml}$ & 3256.12 & 1.0 & 7453 \\
\hline 2 & $100 \mu \mathrm{g} / \mathrm{ml}$ & 3289.45 & 1.0 & 7654 \\
\hline 3 & $100 \mu \mathrm{g} / \mathrm{ml}$ & 3296.91 & 1.1 & 7458 \\
\hline 4 & $100 \mu \mathrm{g} / \mathrm{ml}$ & 3241.89 & 1.0 & 7412 \\
\hline 5 & $100 \mu \mathrm{g} / \mathrm{ml}$ & 3263.49 & 1.1 & 7463 \\
\hline 6 & $100 \mu \mathrm{g} / \mathrm{ml}$ & 3301.24 & 1.1 & 7401 \\
\hline
\end{tabular}

\section{Intermediate Precision}

\section{Day to day precision}

Table 6: Result of day-to-day intermediate precision of ivacaftor

\begin{tabular}{|c|c|c|c|}
\hline Concentration & $\begin{array}{c}\text { Area } \\
\text { Response }\end{array}$ & $\begin{array}{c}\text { Tailing } \\
\text { Factor }\end{array}$ & $\begin{array}{c}\text { Theoretical } \\
\text { Plate }\end{array}$ \\
\hline $5 \mu \mathrm{g} / \mathrm{ml}$ & 412.146 & 1.0 & 7453 \\
\hline $10 \mu \mathrm{g} / \mathrm{ml}$ & 830.731 & 1.0 & 7654 \\
\hline $15 \mu \mathrm{g} / \mathrm{ml}$ & 1258.961 & 1.1 & 7458 \\
\hline $20 \mu \mathrm{g} / \mathrm{ml}$ & 1664.328 & 1.0 & 7412 \\
\hline $25 \mu \mathrm{g} / \mathrm{ml}$ & 2098.257 & 1.1 & 7463 \\
\hline Value of $\mathbf{R}^{\mathbf{2}}$ & & 0.999 & \\
\hline
\end{tabular}

\section{Robustness}

A working solution of $100 \mu \mathrm{g} / \mathrm{ml}$ (100 PPM) for Ivacaftor was taken and the following method parameters were changed independently of each other.

- Mobile phase ratio ( $\pm 2 \%$ )

- Flow rate $( \pm 0.2 \mathrm{ml} / \mathrm{min})$

Injected three times each with changes in parameters.

Acceptance Criteria: \% RSD Not more than 5.0\% 
Table 7: Robustness of Ivacaftor

\begin{tabular}{|c|c|c|}
\hline Flow rate(ml/min) & Variation & Retention Time \\
\hline 0.8 & -0.2 & 6.05 Minutes \\
\hline 1 & 0 & 5.82 Minutes \\
\hline 1.2 & +0.2 & 5.57 Minutes \\
\hline & RSD\% 4.13 & \\
\hline
\end{tabular}

\begin{tabular}{|c|c|c|c|}
\hline $\begin{array}{c}\text { \% of } \\
\text { Acetonitrile }\end{array}$ & $\begin{array}{c}\text { \% of } \\
\text { Methanol }\end{array}$ & Variation & Retention Time \\
\hline 45 & 25 & $-5 \mathrm{ml}$ & 6.12 Minutes \\
\hline 50 & 30 & 0 & 5.89 Minutes \\
\hline 55 & 35 & $+5 \mathrm{ml}$ & 5.68 Minutes \\
\hline RSD\% & & & $\mathbf{3 . 7}$ \\
\hline
\end{tabular}

limit of Detection (LOD)

The LOD was calculated as $0.1412 \mu \mathrm{g} / \mathrm{ml}$ of Ivacaftor

\section{Limit of Quantification (LOQ)}

The LOQ was calculated as $0.5478 \mu \mathrm{g} / \mathrm{ml}$ of Ivacaftor.

\section{CONCLUSION}

The result shows that developed methods to be Costeffective, Rapid (Short retention time), Simple, Accurate (the value and \%RSD between 2-5), Precise, and can be used for intended purposes on the tablet dosage form. The Simplicity, Rapidly and Reproducibility of the developed method qualify the objective of the research. Results of analysis of the Ivacaftor tablet formulations are arranged in the experimental, result, and discussion section. The portion of Ivacaftor found in terms of quantity was between $98-102 \%$ and also within USP acceptance criteria.

This "New Cost-Effective RP-HPLC Method Development and Validation for Quantitative Estimation of Ivacaftor in Pharmaceutical Formulation" includes RP-HPLC, Spectrophotometric method. The economical and simple HPLC method was optimized during development and validated accordingly in tablets of Ivacaftor. The developed method may utilize for the analysis of Ivacaftor at the laboratory level.

\section{REFERENCES}

1. Ravishankar P, Devadasu C, Shrinivasa D, Rao GD, Gananathamu and Sowjanya S. New spectrophotometric techniques for the quantitative investigation of Ivacaftor in the pharmaceutical dosage form. Int. J. Chem. Sci.2010; 8(4): 2309-24.

2. Gurdeep R. Chatwal, Sham K. Anand, "Instrumental Method of Chemical Analysis," 5th Edition, 2009; PP- 570 and 624, 566-567.

3. A.H. Beckett,J.B. Stenlake, "Practical Pharmaceutical Chemistry," Part - II, 5th Edition, 2015; PP- 279-282 and 287, 273.

4. Sweetman SC.Martindale: The Complete Drug Reference. Pharmaceutical Press, London, 2002; 1: 2188-2197.
5. Arai $\mathrm{Y}$, Ohara H, Ichioka K, Koji $\mathrm{Y}$, Terai A, International Journal of Urology, 2004; 11 (10): 870.

6. K N Vishwottam, N V S Ramakrishna, S Manoj, M Koteshwara, S Wishu, D P Varma, Biomedical Chromatography, 2014; 19: $709-719$.

7. Journal of Chromatography Biomedical Sciences and Application, Issue Nov.2009; (1): PP- 195-199.

8. Goodman SL, Gilman A, General principle. A textbook of pharmacology, toxicology for medicinal students and physicians. New York, MacMillan Company,2000; 2-46.

9. Sethi PD,HPLC quantitative analysis of pharmaceuticals. New Delhi, CBS Publishers \& Distributors, 2000; 1-211.

10. Sethi $P D$, Identification of the drug in pharmaceutical formulations by TLC New Delhi, CDS distributor, 1999; 1-52.

11. Sidney HW, James RS, Good manufacturing practices for pharmaceuticals 5th Edition. U.S.A., 2001; 10-16.

12. Hokanson GC, The initial validation process. A life cycle approach to the validation of analysis method during pharmaceutical product development, Pharm Tech Pub,1994; (I): 118-130.

13. Caruso S, Di ML, Cacciatore A, Mamana G, Agnello C, Cianci A, Prophylaxis with Ivacaftor antibiotic cystic fibrosis. Minerva Ginecol. 2008; 60(1): 1-5.

14. Huang $Y$, Tang $Y$, Liu B, Gao X, Yan J, Zi Y, Yu Z, Spectroc him Acta A Mol Bio mol Spectrosc, 2010; 75(3): 1024-9.

15. Addonisio P, Cai T, Mazzoli S, Pagliai RC, Bechi AN, Bartoletti R, Mondaini N, Int J Anti-microb Agents, 2009; 33(6): 54953.

16. Tang YC, Zi YQ, Huang YB, Wang SJ, Yu Z, Gao XY, Zhang DM, Chem Pharm Bull, 2010; 58(4): 582-6.

17. Yu F, Chen F, Liu W, Cai P, Highly delicate spectrofluorimetric assurance of trace amount of Ivacaftor using the aluminum (III) Ivacaftor system. Luminescence,2008; 23(6): 429-33.

18. Guo L, Qi M, Jin X, Wang P, Zhao H,. Determination of active metabolite of Ivacaftor in human plasma by fluid chromatography-mass spectroscopy. J Chromatogr B AnalytTechnol Biomed Life Sci, 2006; 832(2): 280-5.

19. Zhang L. Li Z. Wen J. Wu Y. Pan Y. Fan G, Biomed Journal of life sciences, 2008; 872(1-2): 172-6.

20. Philip K, Shindler M, Yatoma A, Ciottoli GB,.In vitro and In vivo experiments of cardiac-related disease. Eur J Pharmacol, 2003; 477(1): 69-72.

21. D. R. Chaple, A. G. Sambhar. Validated stability indicating HPLC method for Ivacaftor. International Journal of Pharmacy and Technology.2010; 1(2): 137-148.

22. Schreiber MS, "Chromatography-an Historical Dialogue", 8thNew York, Elsevier Scientific Publishing Company 1975; 413.

23. Pokharkar D. JadhavV. GholveS. Kadam V. estimation of Ivacaftor in tablet dosage form. Int. Journal of Pharm tech research. 2010: 2(1): 960-963.

24. Brown RP, Gruskha E. Advance in chromatography. Marcel Dekker Inc. 2003: 42; 95. 
25. Valcarcell M, CastroLuque MD. Automatic methods of analysis, Elsevier publisher B.V, 1988: 9; 369-377.

26. Shankar RS. High-Performance Liquid Chromatography. Textbook of pharmaceutical analysis, 1st edition. Madras, Neelmia Printers, 1997 ; $18-1$ to $18-15$.

27. Mansoor AK, Indra KR. Pharmaceutical and clinical calculations. Florida, CRC Press LLC, 2000.
28. Gennaro AR. Remingtons the science and practice of pharmacy 19th edition. Mack Publishing Company; 1995.

29. David NM. High-performance LC in chromatography in pharmaceutical bio-analysis. A handbook of bio-analysis and drug metabolism, Florida, CRC Press LLC; 2000: 4.1-4.8.

30. Veerendra K. Nanjwade, FV Manvi, Shamrez Ali. M, Basavaraj K. Nanjwade, Development and evaluation of Ivacaftor tablet. Int. journal of drug formulations and research. $2011 ; 2(6)$ : 302-314.

Source of Support: The author(s) received no financial support for the research, authorship, and/or publication of this article.

Conflict of Interest: The author(s) declared no potential conflicts of interest with respect to the research, authorship, and/or publication of this article.

For any question relates to this article, please reach us at: editor@globalresearchonline.net

New manuscripts for publication can be submitted at: submit@globalresearchonline.net and submit_ijpsrr@rediffmail.com 